\title{
PENERAPAN METODE WEIGHTED PRODUCT PADA SISTEM PENUNJANG KEPUTUSAN UNTUK PEMILIHAN ANGGOTA TERBAIK NAPOSO
}

\author{
Martin Hasiholan Natanael ${ }^{1}$, Dewi Kusumaningsih ${ }^{2}$ \\ ${ }^{1}$ Teknik Informatika, Universitas Budiluhur \\ e-mail: '1martin.lumbanraja@gmail.com \\ ${ }^{2}$ Teknik Informatika, Universitas Budiluhur \\ e-mail: ${ }^{2}$ Dewi.kusumaningsih@budiluhur.ac.id
}

\begin{abstract}
Abstrak
Pada proses pemilihan anggota terbaik masih dilakukan secara manual dengan satu kriteria. Bertambahnya kriteria baru dan jumlah alternatif yang banyak menjadi dasar bagi peneliti unuk membangun sistem penunjang keputusan pemilihan anggota terbaik. Metode yang digunakan dalam penelitian ini adalah Weighted product (WP) dengan beberapa kriteria yang telah ditambahkan yaitu absen pendalaman alkitab, jumlah kegiatan, kedisiplinan dan jarak dari rumah. Dari perbandingan antara perhitungan manual dan perhitungan sistem dengan kriteria baru, didapat peningkatan akurasi peringkat sebesar $90 \%$. Oleh karena itu penilitian ini dapat digunakan sebagai alat bantu untuk menentukan anggota terbaik.
\end{abstract}

Keywords: Weighted product, Sistem Pendukung Keputusan, Sistem Perhitungan, Multi Attribute Decision Making, Sistem Aplikasi

\section{Pendahuluan}

Seiring dengan perkembangan tempat hiburan membuat anggota naposo semakin mengurangi keterlibatannya dalam lingkungan gereja. Hal ini tentu berdampak pada menurunnya produktivitas naposo sebagai penerus gereja, sehingga dibutuhkan peningkatan naposo. Salah satu cara yaitu pemilihan anggota terbaik oleh pengurus naposo.

Pemilihan anggota terbaik merupakan suatu bentuk apresiasi yang dapat memacu semangat anggota naposo untuk terlibat aktif dan produktif. Proses pemilihan anggota terbaik masih menggunakan cara manual dan belum memakai sistem. Masalah timbul dalam proses penilaian kriteria-kriteria karena banyak alternatif yang bisa dipilih dan tidak adanya pengarsipan data penilaian sebagai acuan pemilihan anggota terbaik periode berikutnya, sehingga proses penilaian kurang efektif dan efisien (Yoni and Mustafidah, 2016). Maka dibutuhkan sistem pendukung keputusan untuk membantu proses pemilihan anggota terbaik(Dona, Yasdomi and Utami, 2018).

Sistem pendukung keputusan (SPK) adalah suatu sistem berbasis komputer yang digunakan untuk mendukung pengambilan keputusan. SPK bertujuan untuk menyediakan informasi, membimbing, memberikan prediksi terhadap alternatif mana yang memiliki nilai terbaik dari setiap kriteria(Sambani, Agustin and Marlina, 2016). Terdapat beberapa metode SPK yang dapat digunakan, yaitu Simple Additive Weighting (SAW), Weighted product (WP), Technique for Order Preference by Similiarity to Ideal Solution (TOPSIS), Profile Matching, Analytic Hierarchy Process (AHP)(Oktavia, 2018).

Metode Weighted product (WP) merupakan metode penyelesaian untuk menyelesaikan masalah Multi Attribute Decision Making (MADM)(Niza, 2019). Menggunakan metode WP ini lebih efisien karena waktu yang lebih singkat, dengan penentuan nilai bobot untuk setiap atribut dan dilanjutkan dengan proses perangkingan yang menentukan anggota terbaik sesuai kriteria(Muslihudin and Rahayu, 2018). Berdasarkan kesimpulan dari hasil penelitian sebelumnya, dapat disimpulkan bahwa menggunakan metode WP lebih baik dari pada metode SAW, yaitu nilai presentase kesesuaian antara $99.7991 \%$ pada metode SAW dengan 99.8006\% pada metode WP(Sri Mulyani, Hidayat and Julyani, 2019). 
Beberapa artikel yang dapat digunakan sebagai landasan teori pada penelitian ini, seperti penelitian yang dilakukan oleh Nur Rohmah, dkk yang berjudul "Penerapan Metode Weighted product (WP) untuk Penerimaan Pegawai Baru di Pt. Tiga Serangkai Pustaka Mandiri Surakarta"(Rohmah, Remawati and KKW, 2016). Penelitian selanjutnya dilakukan oleh Nasrun Marpaung, dkk yang berjudul "Sistem Pendukung Keputusan Pemilihan Dosen Terbaik dengan Metode Weighted product (WP) pada STMIK Royal"(Marpaung, Handayani and Yesputra, 2018). Selanjutnya penelitian juga dilakukan oleh Arman, dkk yang berjudul "Sistem Pendukung Keputusan Pemilihan Guru Terbaik dengan Metode Weighted product pada MAN 1 Pariaman"(Arman et al., 2019).

\section{Metodologi Penelitian}

Pada penelitian kali ini akan menggunakan Metode Pengembangan Perangkat Lunak (MPPL), yaitu mengembangkan sistem pendukung keputusan dalam memilih anggota naposo terbaik, dengan menggunakan data yang didapat langsung dari pengurus naposo bidang penelitian dan pengembangan. Metode ini mempunyai beberapa model pengembangan, yang paling populer diantaranya adalah metode waterfall, parallel, prototype, spiral, rad dan agile(Bolung and Tampangela, 2017).

Sistem pendukung keputusan yang akan dibangun menggunakan model waterfall. Model waterfall merupakan MPPL tradisional yang sistematis dengan tahapan :

\section{Requirement Analysis}

Tahap ini memerlukan komunikasi yang bertujuan untuk memahami perangkat lunak yang diharapkan oleh pengguna. Informasi ini diperoleh melalui wawancara, diskusi dan survei langsung.

2. System and Software Design

Spesifikasi kebutuhan dari tahap sebelumnya akan dipelajari dalam fase ini dan desain sistem disiapkan. Tahapan perancangan sistem mengalokasikan kebutuhan-kebutuhan sistem baik perangkat keras maupun perangkat lunak dengan membentuk arsitektur sistem secara keseluruhan.

\section{Implementation and Unit Testing}

Pada tahap ini sistem mulai dikembangkan sebagai serangkaian unit program sesuai dengan System Design, yang disebut dengan unit testing

\section{Integration and System Testing}

Seluruh unit yang dikembangkan dalam tahap implementasi diintegrasikan ke dalam sistem setelah pengujian yang dilakukan masingmasing unit.

\section{Operation and Maintenance}

Tahap akhir dalam model waterfall. Perangkat lunak yang sudah jadi, dijalankan serta dilakukan pemeliharaan(Mustafidah and Hadyan, 2017).

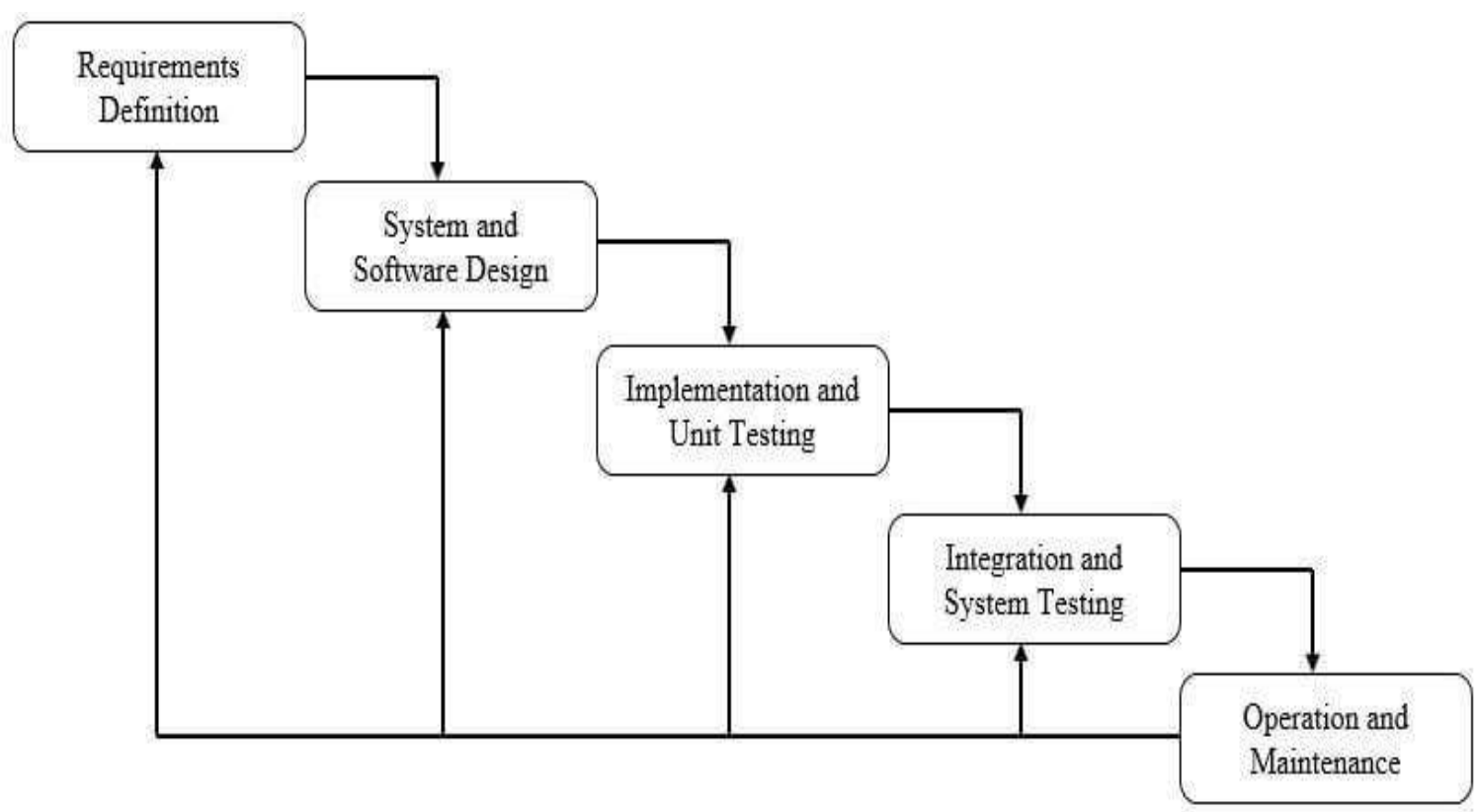

Gambar 1. Tahapan SDLC Model Waterfall 
Adapun teknik pengumpulan data pada penelitian ini adalah :

1. Observasi

Penulis melakukan pengamatan langsung ke tempat objek pembahasan untuk memahami situasi dan kondisi pada naposo.

2. Wawancara

Penulis melakukan wawancara dengan memberi beberapa pertanyaan, untuk mendapatkan penjelasan lebih lanjut mengenai masalah-masalah yang ada dan untuk memastikan bahwa data yang diperoleh telah valid.

3. Studi Pustaka

Penulis mencari referensi dan mengutip dari beberapa bacaan yang berkaitan dengan pelaksanaan penelitian ini(Ernawati, Aeni Hidayah and Fetrina, 2017).

\section{HASIL DAN PEMBAHASAN}

A. Analisa Kebutuhan dan Pengumpulan Data

Setelah melakukan pengamatan langsung, wawancara dan studi literature menghasilkan sistem pendukung keputusan dengan metode Weighted product untuk menyelesaikan masalah pada naposo.

\section{B. Perancangan dan Pembuatan Aplikasi}

Berdasarkan pengumpulan data dari hasil analisa kebutuhan, maka dibutuhkan perhitungan metode Weighted product sebagai landasan sistem dalam menghasilkan keluaran alternatif dengan nilai tertinggi dibandingkan nilai alternatif yang lain. Hasil keluaran berasal dari perhitungan kriteria dengan bobot yang berbeda. Pada penelitian kali ini perhitungan Weighted product memiliki lima langkah yang digambarkan menggunakan flowchart.

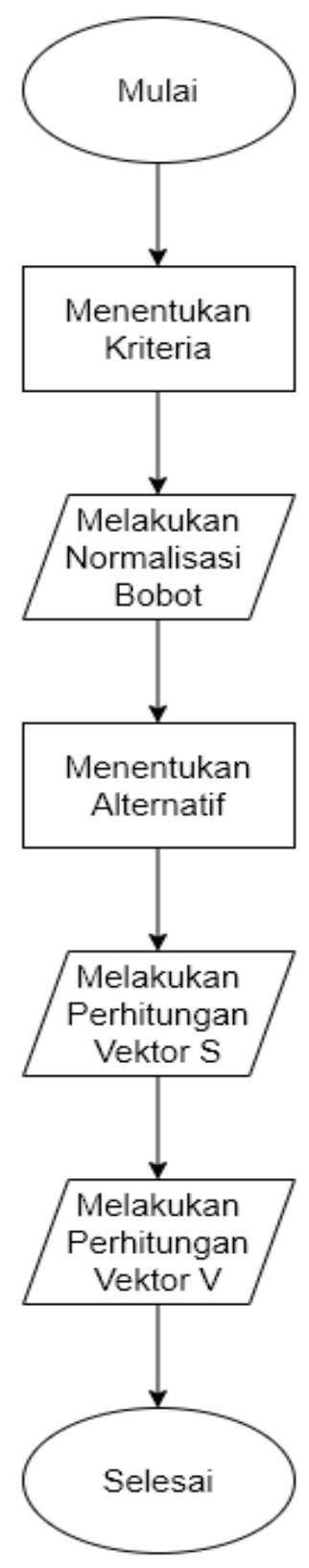

\section{Gambar 2. Flowchart Weighted product}

1. Menentukan Kriteria

Ada empat kriteria bertipe benefit dengan bobot berbeda, yaitu Absen Pendalaman Alkitab, Jumlah Kegiatan, Kedisiplinan, dan Jarak dari Rumah. Selanjutnya pihak pengurus menentukan bobot masing-masing kriteria : 
Tabel 1. Kriteria

\begin{tabular}{ccc}
\hline Nama Kriteria & $\begin{array}{c}\text { Tipe } \\
\text { Kriteria }\end{array}$ & $\begin{array}{c}\text { Bobot } \\
\text { Kriteria }\end{array}$ \\
\hline (C1) Absen Pendalaman & Benefit & 4 \\
Alkitab & & \\
(C2) Jumlah Kegiatan & Benefit & 3 \\
(C3) Kedisiplinan & Benefit & 2 \\
(C4) Jarak Dari Rumah & Benefit & 1 \\
\hline
\end{tabular}

2. Normalisasi Bobot

Selanjutnya pada bobot kriteria dilakukan normalisasi dengan menggunakan rumus sebagai berikut :

$$
W j=\frac{W j}{\sum W j}(1)
$$

$\mathrm{Wj}$ adalah nilai bobot pada kriteria

$$
W 1=\frac{4}{4+3+2+1}=0.4
$$

\section{Menentukan Alternatif}

Alternatif yang dimaksud adalah anggota naposo. Data alternatif yang telah

$$
\begin{aligned}
& W 2=\frac{3}{4+3+2+1}=0.3 \\
& W 3=\frac{2}{4+3+2+1}=0.2 \\
& W 4=\frac{1}{4+3+2+1}=0.1
\end{aligned}
$$

Tabel 2. Bobot Kriteria

\begin{tabular}{ccc}
\hline $\begin{array}{c}\text { Nama } \\
\text { Kriteria }\end{array}$ & Bobot & $\begin{array}{c}\text { Hasil Normalisasi } \\
\text { Bobot }\end{array}$ \\
\hline $\begin{array}{c}\text { (C1) Absen } \\
\text { Pendalaman } \\
\text { Alkitab }\end{array}$ & $4 / 10$ & 0.4 \\
$\begin{array}{c}\text { (C2) Jumlah } \\
\text { Kegiatan }\end{array}$ & $3 / 10$ & 0.3 \\
$\begin{array}{c}\text { (C3) } \\
\text { Kedisiplinan } \\
\text { (C4) Jarak }\end{array}$ & $2 / 10$ & 0.2 \\
Dari Rumah & $1 / 10$ & 0.1 \\
\hline
\end{tabular}

diterima dari pengurus naposo untuk rekomendasi anggota terbaik adalah sebagai berikut

Tabel 3. Alternatif

\begin{tabular}{ccccc}
\hline Alternatif & C1 & C2 & C3 & C4 \\
\hline (A1) Dhani Siregar & 75 & 85 & 70 & 85 \\
(A2) Eirene Nadeak & 95 & 80 & 90 & 75 \\
(A3) Intan Silaban & 90 & 80 & 85 & 80 \\
(A4) Jeges Simanjuntak & 90 & 85 & 85 & 80 \\
(A5) Jimmy Nadeak & 85 & 90 & 80 & 75 \\
(A6) Martin Nainggolan & 85 & 95 & 90 & 70 \\
(A7) Meri Simanjuntak & 80 & 90 & 80 & 95 \\
(A8) Rico Panjaitan & 85 & 90 & 85 & 90 \\
(A9) Sabam Manulang & 80 & 85 & 95 & 90 \\
(A10) Tian Simanungkalit & 75 & 80 & 85 & 80 \\
\hline
\end{tabular}

4. Melakukan Perhitungan Vektor $S$

Mencari nilai vektor $S$ dengan cara nilai setiap kriteria dari alternatif dipangkatkan dengan bobot global

$$
S i=\prod_{j=1}^{\substack{n \\ n}} X i j^{W j}
$$

Tabel 4. Perhitungan Vektor S

\begin{tabular}{ccc}
\hline Alternatif & \multicolumn{1}{c}{ Perhitungan Vektor S } & Hasil Vektor S \\
\hline A1 & $\left(75^{0.4}\right) \times\left(85^{0.3}\right) \times\left(70^{0.2}\right) \times\left(85^{0.1}\right)$ & $\mathrm{S} 1=77.76993$ \\
A2 & $\left(95^{0.4}\right) \times\left(80^{0.3}\right) \times\left(90^{0.2}\right) \times\left(75^{0.1}\right)$ & $\mathrm{S} 2=87.17081$ \\
A3 & $\left(90^{0.4}\right) \times\left(80^{0.3}\right) \times\left(85^{0.2}\right) \times\left(80^{0.1}\right)$ & $\mathrm{S} 3=84.88223$
\end{tabular}




\begin{tabular}{clc} 
A4 & $\left(90^{0.4}\right) \times\left(85^{0.3}\right) \times\left(85^{0.2}\right) \times\left(80^{0.1}\right)$ & $\mathrm{S} 4=86.44014$ \\
A5 & $\left(85^{0.4}\right) \times\left(90^{0.3}\right) \times\left(80^{0.2}\right) \times\left(75^{0.1}\right)$ & $\mathrm{S} 5=84.36541$ \\
A6 & $\left(85^{0.4}\right) \times\left(95^{0.3}\right) \times\left(90^{0.2}\right) \times\left(70^{0.1}\right)$ & $\mathrm{S} 6=87.18524$ \\
A7 & $\left(80^{0.4}\right) \times\left(90^{0.3}\right) \times\left(80^{0.2}\right) \times\left(95^{0.1}\right)$ & $\mathrm{S} 7=84.31389$ \\
A8 & $\left(85^{0.4}\right) \times\left(90^{0.3}\right) \times\left(85^{0.2}\right) \times\left(90^{0.1}\right)$ & $\mathrm{S} 8=86.96577$ \\
A9 & $\left(80^{0.4}\right) \times\left(85^{0.3}\right) \times\left(95^{0.2}\right) \times\left(90^{0.1}\right)$ & $\mathrm{S} 9=85.31603$ \\
A10 & $\left(75^{0.4}\right) \times\left(80^{0.3}\right) \times\left(85^{0.2}\right) \times\left(80^{0.1}\right)$ & $\mathrm{S} 10=78.91222$ \\
\hline
\end{tabular}

5. Melakukan Perhitungan Vektor V Mencari nilai vektor $\mathrm{V}$ dengan cara nilai vektor $\mathrm{S}$ alternatif dibagi dengan jumlah total nilai vektor $\mathrm{S}$

$$
V i=\frac{S i}{\sum S i}
$$

\begin{tabular}{|c|c|c|}
\hline Vektor S & Perhitungan Vektor V & Hasil Vektor V \\
\hline \multirow{2}{*}{ S1 } & 77.76993 & \multirow{2}{*}{$\mathrm{V} 1=0.09222$} \\
\hline & $\overline{S 1+S 2+S 3+S 4+S 5+S 6+S 7+S 8+S 9+S 10}$ & \\
\hline $\mathrm{S} 2$ & $\overline{S 1+S 2+S 3+S 4+S 5+S 6+S 7+S 8+S 9+S 10}$ & $\mathrm{~V} 2=0.10337$ \\
\hline S3 & $\overline{S 1+S 2+S 3+S 4+S 5+S 6+S 7+S 8+S 9+S 10}$ & $\mathrm{~V} 3=0.10065$ \\
\hline S4 & $\overline{S 1+S 2+S 3+S 4+S 5+S 6+S 7+S 8+S 9+S 10}$ & $\mathrm{~V} 4=0.10250$ \\
\hline S5 & $\overline{S 1+S 2+S 3+S 4+S 5+S 6+S 7+S 8+S 9+S 10}$ & $\mathrm{~V} 5=0.10004$ \\
\hline S6 & $\overline{S 1+S 2+S 3+S 4+S 5+S 6+S 7+S 8+S 9+S 10}$ & $\mathrm{~V} 6=0.10338$ \\
\hline S7 & $\overline{S 1+S 2+S 3+S 4+S 5+S 6+S 7+S 8+S 9+S 10}$ & $\mathrm{~V} 7=0.09998$ \\
\hline S8 & $\overline{S 1+S 2+S 3+S 4+S 5+S 6+S 7+S 8+S 9+S 10}$ & $\mathrm{~V} 8=0.10312$ \\
\hline S9 & $\begin{array}{c}S 1+S 2+S 3+S 4+S 5+S 6+S 7+S 8+S 9+S 10 \\
78.91222\end{array}$ & $\mathrm{~V} 9=0.10117$ \\
\hline S10 & $S 1+S 2+S 3+S 4+S 5+S 6+S 7+S 8$ & $\mathrm{~V} 10=0.09357$ \\
\hline
\end{tabular}

Tabel 5. Perhitungan Vektor V 


\section{Use Case Diagram}

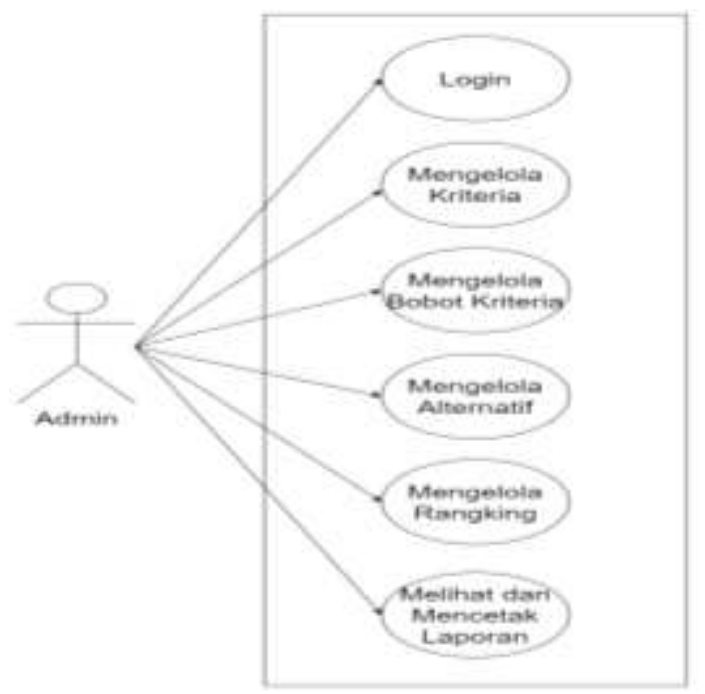

Gambar 3. Use Case Diagram

\section{Implementasi Aplikasi}

Pada tahap ini aplikasi telah siap digunakan. Berikut ini beberapa tampilan dan penjelasannya

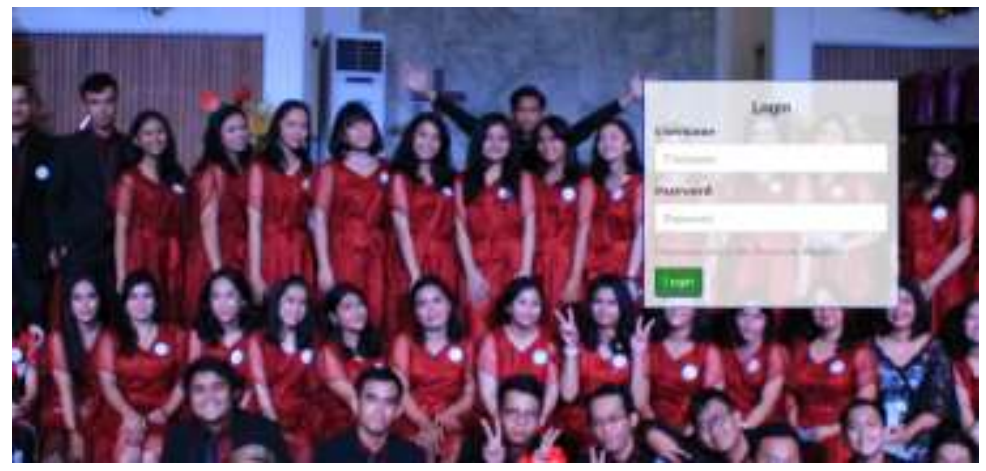

Gambar 4. Tampilan Login

Halaman login pada gambar 4 adalah halaman awal saat membuka aplikasi, digunakan untuk memastikan bahwa user adalah orang yang memiliki izin akses untuk mengubah data masukan.

\begin{tabular}{|c|c|c|c|c|c|c|}
\hline \multirow{2}{*}{ Nhernassf } & \multicolumn{4}{|c|}{ Nriterin } & \multirow{2}{*}{ Velators } & \multirow{2}{*}{ velator $\mathrm{V}$} \\
\hline & Abses Penitskaman Alkitab & Jumtah Keglatan & Kinedistplinan & Jarak Darr Rumah & & \\
\hline Dhaai Siregat & 5.68373 & 3.0153 & $=3.35094$ & $15 \$ 934$ & 77.7690 & $0.09 a 28$ \\
\hline Elrene Nadeak & 6.18144 & $3.7 \times 350$ & 2usast & Isoms & thotrosi & 0.1033 \\
\hline futan Sitabaal & 6ougs: & $x+2309$ & $24315 s$ & Lasigpa: & B.88z23 & 0,00000 s \\
\hline Jeges Stmanfiantak & 6.049t9 & 3.9.9163: & 243155 & L.S199: & 86.4914 & 0,00250 . \\
\hline Mimsay Nadeak & 590245 & $3 \times 521$ & taoers: & 1.53995 & 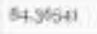 & 0.40004 \\
\hline SAartia Nairueglen & 590245 & 392058 & $2-49951$ & 159336 & 6. 285524 & $0 .+60395$ \\
\hline Steri Simazajumtak & 5 Truso & 38751 & 2.49225 & $+4,9 \times 6 \times 8$ & 4,31380 & 0.050 afi \\
\hline Rics Patulastan & 501245 & 3852 & 24354 & $1,968: 8$ & 6.96,as? & 0.0030 \\
\hline Sabam Mamulang & $\$ 77080$ & 3 3.915s & 2.48605 & $7.56 \mathrm{As} 8$ & 53.3600 & o.10u1t \\
\hline Tlas Simaaniaklollt & 3.62373 & 3.72329 & 2.4355 & I.34992 & 28.91228 & 0.05357 \\
\hline
\end{tabular}

Gambar 5. Perangkingan Metode Weighted product 
Gambar 5 adalah tampilan peringkat perhitungan metode Weighted product, berguna untuk memberikan informasi hasil dari perangkingan metode Weighted product berdasarkan nilai yang telah di masukkan sebelumnya.

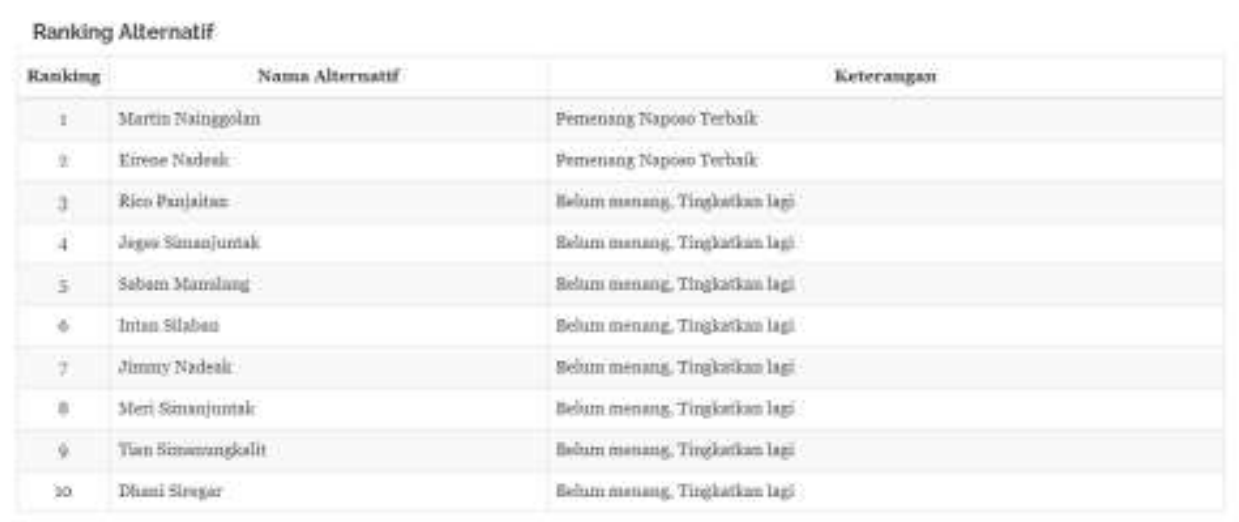

Gambar 6. Rangking Alternatif

Gambar 6 adalah tampilan urutan peringkat dari hasil perhitungan metode Weighted product, dimana peringkat diurutkan dari hasil nilai terbesar ke hasil nilai terkecil.

\section{E. Perbandingan Perhitungan}

Berdasarkan perbandingan perhitungan antara perhitungan manual sebelum sistem dibuat dan metode weighted product, didapat peningkatan akurasi perhitungan sebesar $90 \%$.

Tabel 6. Perbandingan Perhitungan

\begin{tabular}{cccc}
\hline Alternatif & P1 & Kenyataan & P2 \\
\hline A1 & 9 & 10 & 10 \\
A2 & 1 & 2 & 2 \\
A3 & 2 & 6 & 6 \\
A4 & 2 & 4 & 4 \\
A5 & 4 & 7 & 7 \\
A6 & 4 & 1 & 1 \\
A7 & 7 & 8 & 8 \\
A8 & 4 & 3 & 3 \\
A9 & 7 & 5 & 5 \\
A10 & 9 & 9 & 9 \\
Akurasi & $10 \%$ & & !00\% \\
\hline
\end{tabular}

\section{Keterangan :}

P1 = Peringkat berdasarkan perhitungan manual

$\mathrm{P} 2=$ Peringkat berdasarkan perhitungan sistem

\section{Kesimpulan}

Berdasarkan hasil dari sistem pendukung keputusan dengan metode Weighted product untuk pemilihan naposo terbaik, dapat disimpulkan sebagai berikut :

1. Sistem yang dibangun oleh penulis bisa membantu pengurus menyelesaikan masalah yang ada, karena kriteria yang

lebih spesifik dengan kriteria baru yang telah ditambahkan

2. Menggunakan sistem pendukung keputusan dengan metode Weighted product lebih efisien untuk menentukan anggota terbaik dengan berpotensi meningkatkan produktivitas naposo

3. Sistem yang dibangun penulis menggunakan kriteria tidak tetap 
sehingga bisa dimodifikasi oleh pengurus sesuai kebutuhan

\section{Referensi}

[1] Arman et al. (2019) "Sistem Pendukung Keputusan Pemilihan Guru Terbaik dengan Metode Weighted product Pada MAN 1 Pariaman," Jurnal Informatika, 6(2), pp. 310-321.

[2] Bolung, M. and Tampangela, H. R. K. (2017) "Analisa Penggunaan Metodologi Pengembangan Perangkat Lunak," Jurnal ELTIKOM, 1(1), pp. 1-10. doi: 10.31961/eltikom.v1i1.1.

[3] Dona, Yasdomi, K. and Utami, U. (2018) "Sistem Pendukung Keputusan Karyawan Terbaik Menggunakan Metode Weight Product ( WP ) ( Studi Kasus : Universitas Pasir Pengaraian )," 4(1), pp. 129-143.

[4] Ernawati, Aeni Hidayah, N. and Fetrina, E. (2017) "RANCANG BANGUN SISTEM PENDUKUNG KEPUTUSAN KENAIKAN JABATAN PEGAWAI DENGAN METODE PROFILE MATCHING (Studi Kasus: Kementerian Agama Kantor Wilayah DKI Jakarta)," Studia Informatika: Jurnal Sistem Informasi, 10(2), pp. 127-134.

[5] Marpaung, N., Handayani, M. and Yesputra, R. (2018) "Sistem Pendukung Keputusan Pemilihan Dosen Terbaik Dengan Metode Weighted product (WP) Pada STMIK Royal," Seminar Nasional Royal 2018, 9986(September), pp. 267270.

[6] Muslihudin, M. and Rahayu, D. (2018) "Sistem Pendukung Keputusan Siswa Berpretasi Menggunakan Metode Weighted product," Jurnal TAM (Acceptance Model), 9(2), pp. 114-119.

[7] Mustafidah, H. and Hadyan, H. N. (2017) "Sistem Pendukung Keputusan Penentuan Mahasiswa Berprestasi di Universitas Muhammadiyah Purwokerto Menggunakan Metode Weighted product ( WP ) ( Decision Support System of Excellent Student Determination in Universitas Muhammadiyah Purwokerto Using Weighted," Juita, 5(1), pp. 51-61.
Available at: http://jurnalnasional.ump.ac.id/index.php /JUITA/article/view/1846/1539.

[8] Niza, R. P. (2019) "SISTEM PENDUKUNG KEPUTUSAN PENERIMAAN SISWA BARU PADA SMA PGRI 4 PADANG MENGGUNAKAN METODE WEIGHTED PRODUCT (WP)," 2(2), pp. $1-14$.

[9] Oktavia, P. (2018) "Sistem Pendukung Keputusan Seleksi Penerima Beasiswa dengan Metode Weighted product pada SMP Negeri 1 Parung Berbasis Web," Jurnal Informatika Universitas Pamulang, 3(2), p. $80 . \quad$ doi: 10.32493/informatika.v3i2.1432.

[10] Rohmah, N., Remawati, D. and KKW, A. (2016) "Penerapan Metode Weighted product (Wp) Untuk Penerimaan Pegawai Baru Di Pt. Tiga Serangkai Pustaka Mandiri Surakarta," Jurnal Ilmiah SINUS, 14, pp. 41-58.

[11] Sambani, E. B., Agustin, Y. H. and Marlina, R. (2016) "Sistem Pendukung keputusan Kenaikan Jabatan Karyawan Plaza Asia Dengan Menggunakan Metode Weighted product," CSRID (Computer Science Research and Its Development Journal), 8(2), p. 121. doi: 10.22303/csrid.8.2.2016.121-130.

[12] Sri Mulyani, E. D., Hidayat, C. R. and Julyani, G. S. (2019) "Analisis Perbandingan Sistem Pendukung Keputusan Menggunakan Metode SAW Dengan WP Dalam Pemberian Pinjaman," CogITo Smart Journal, 5(2), p. $239 . \quad$ doi: 10.31154/cogito.v5i2.151.239-251.

[13] Yoni, D. C. and Mustafidah, H. (2016) "Penerapan Metode WP (Weighted product) Untuk Pemilihan Mahasiswa Lulusan Terbaik di Fakultas Teknik Universitas Muhammadiyah Purwokerto," Juita, IV(1), pp. 22-27. Available at: http://jurnalnasional.ump.ac.id/index.php /JUITA/article/view/1184. 